\title{
Dynamic Bargaining with Transaction Costs
}

\author{
PETER C. CRAMTON
}

Yale School of Management, Box 1A, New Haven, CT 06520

\begin{abstract}
A buyer and seller alternate making offers until an offer is accepted or someone terminates negotiations. The seller's valuation is common knowledge, but the buyer's valuation is known only by the buyer. Impatience to reach an agreement comes from two sources: the traders discount future payoffs and there are transaction costs of bargaining. Equilibrium behavior involves either immediate trade, delayed trade, or immediate termination, depending on the size of the gains from trade and the relative bargaining costs. This contrasts with the pure discounting model where termination never occurs, and the pure transaction cost model where delayed trade never occurs.
\end{abstract}

\section{Introduction}

In his analysis of the economics of bargaining, Cross 1969 emphasizes the importance of time and bargaining costs on the negotiation process:

The most important characterization which we, in this study, will apply to the bargaining process is that it is fundamentally time dependent. It is widely appreciated that the passage of time has a cost in terms of both dollars and the sacrifice of utility which stems from the postponement of consumption, and it will be our position throughout this study that it is precisely this cost which motivates the whole process. If it did not matter when the parties agreed, it would not matter whether or not they agreed at all.

The recent literature on strategic bargaining also takes this view. ${ }^{1}$ The bargaining process is modeled as the exchange of offers by impatient bargainers until an acceptable offer is made or negotiations are terminated. Most studies of dynamic bargaining assume that the sole source of the bargainers' impatience is the discounting of future payoffs. One notable exception is Perry 1986, which analyzes an alternatingoffer bargaining model in which there is a transaction cost associated with each period of delay. Even though there is private information about valuations, in equilibrium trade occurs immediately or not at all; hence, with positive probability the bargaining ends despite the fact that gains from trade still exist. The party with the smaller bargaining cost makes a single take-it-or-leave-it offer to the other. This result is in sharp contrast to the results of discounting models, where the bargaining continues until the traders are convinced that gains are not possible. ${ }^{2}$ 
Here I analyze a model with two sources of impatience: the traders discount future payoffs and there is a transaction cost of bargaining. The transaction cost, for example, might be the hourly fee of the agent who is conducting the negotiation, a fee paid to a mediator or arbitrator, or the opportunity wage of the trader. In light of the sharp contrast between the models with discounting and Perry's model with a transaction cost but no discounting, it is important to analyze the case with both discounting and transaction costs. Does equilibrium behavior with both sources of impatience look more like the take-orleave-it bargaining of the transaction cost model or more like the sustained bargaining of the discounting models? How does the behavior change as transaction costs become more or less important than discounting? To what extent is a bargainer hurt by having higher bargaining costs than the other bargainer? I explore these questions in a setting similar to Cramton 1991, but with transaction costs introduced and only one-sided uncertainty.

The traders' bargaining is modeled as an infinite-horizon extensive-form game in which the traders alternate making offers as in Rubinstein 1982. However, following Admati and Perry 1987, a trader is able to delay making an offer and the other trader must wait until a counter-offer is made before he can revise his previous offer. Allowing the traders to delay offers permits the construction of a signalling equilibrium in which the informed bargainer signals the strength of his bargaining position through his willingness to delay settlement. ${ }^{3}$ The signalling equilibrium has two advantages. First, the equilibrium is easily calculated from a simple incentive constraint and a single-variable maximization problem, so comparative statics results can be obtained. Second, the equilibrium does not satisfy the Coase property (Gul and Sonnenschein 1988 and Gul, Sonnenschein, and Wilson 1986), which dictates that the uninformed party lose all her bargaining power as the time between offers goes to zero. Hence, the outcome in the signalling equilibrium does not depend critically on the minimum time between offers.

Despite the virtues of the signalling equilibrium, it can be criticized on the grounds that it is based on an extensive form that introduces unreasonable commitments; namely, the uninformed party is able to commit not to revise her offer, while she is waiting for the informed party to respond. ${ }^{4}$ If her initial offer is not immediately accepted, the uninformed party has an incentive to revise it. What is keeping her from making a more attractive offer to speed up the negotiation process? One story is that if she were to revise her offer she would lose her reputation for being a tough bargainer and the other would expect additional concessions. By not revising her offer she preserves her reputation and is able to settle at more attractive terms. The difficulty with this approach is that reputational stories can be used to identify a vast set of equilibria of which the signalling equilibrium is just one (see Ausubel and Deneckere 1989a,b). Nonetheless, I view the signalling equilibrium as a practical alternative to the screening equilibria in Grossman and Perry 1986 and Gul and Sonnenschein 1988. Only empirical and experimental tests can shed light on which equilibrium is a better predictor of negotiator behavior. ${ }^{5}$

My analysis shows that when discounting is added to the transaction cost model the take-it-or-leaveit equilibrium of Perry persists only when one trader has a significant cost advantage. Otherwise, the equilibrium is similar to that of the discounting model. The seller makes an offer at the outset of negotiations that is accepted if the buyer's valuation is sufficiently high. If the buyer's valuation is in a middle range, the buyer rejects the seller's offer and makes a counteroffer after delaying long enough to signal his valuation. The transaction cost, however, does alter the bargaining in a fundamental way: if the buyer's valuation is sufficiently low, the buyer immediately terminates negotiations, because his gross profits from trade are smaller than his transaction costs. Thus, the bargaining model has the prominent features of both the discounting and the transaction cost models. Trade often occurs after delay due to the private information about the buyer's valuation, but sometimes the gains from trade are lost because a bargainer terminates negotiations.

1985, Grossman and Perry 1986, Gul and Sonnenschein 1988, Gul, Sonnenschein, and Wilson 1986, Hart 1988, Rubinstein 1985, and Sobel and Takahashi 1983. For analyses with two-sided uncertainty see Ausubel and Deneckere 1988a, Chatterjee and Samuelson 1987, Cho 1990,

Cramton 1984, 1985, 1991, and Fudenberg and Tirole 1983.

3.I do not consider the question of uniqueness. See Admati and Perry 1987 for conditions under which the signalling equilibrium is unique in a model without transaction costs.

4. See Perry and Reny 1989 for an extensive form that relaxes this controversial feature.

5 .Preliminary empirical work has already begun. Kennan and Wilson 1989 discuss data on union contract negotiations and show how the data can be used to empirically test the screening equilibrium. Cramton and Tracy 1990 derive the signalling equilibrium in a related model of wage bargaining. They show that many of the key features of collective bargaining data are consistent with the signalling theory. 
The paper is organized as follows. I begin by describing the model (§2). Next, the equilibrium beliefs and strategies are derived (§3). Finally, I turn to an example with uniform uncertainty to assess how the bargaining outcome changes with changes in the bargainers' transaction costs $(\S 4)$. Proofs are relegated to the appendix.

\section{Formulation}

There are two traders, a seller $(S)$ and a buyer $(B)$. It is common knowledge that the seller's valuation is $S$, which we normalize to be 0 , but only the buyer knows his valuation $B$. Ex ante, the traders share the belief that the buyer's valuation $B$ is drawn from the distribution $F$ with positive density $f$ on $[l$, $h$ ]. The traders discount future payoffs according to the discount rate $r .{ }^{6}$ In addition, there are transaction costs of bargaining, which are assumed to be proportional to the duration of negotiations. Let $c_{S}$ and $c_{B}$ be the costs per unit time of negotiating for $S$ and $B$, respectively. This opportunity cost is paid until trade takes place or one of the traders terminates negotiations. The cost to player $i$ if negotiations continue until time $t$ is $\left(c_{i} / r\right)\left(1-e^{-r t}\right) ; c_{i} / r$ is the present value of a perpetuity of $c_{i}$ starting today and $\left(c_{i} / r\right) \mathrm{e}^{-r t}$ is the present value of a perpetuity of $c_{i}$ starting at time $t$, so the difference is the present value of $c_{i}$ paid from today until time $t$.

The outcome of the game if trade occurs is given by a time of trade $t$ and price $p$. Given the outcome $\langle t, p\rangle, S^{\prime}$ s payoff $u_{S}(S, t, p)$ and $B^{\prime}$ 's payoff $u_{B}(B, t, p)$ are given by

$$
\begin{aligned}
& u_{s}(S, t, p)=(p-S) e^{-r t}-\frac{c_{s}}{r}\left(1-e^{-r t}\right), \\
& u_{B}(B, t, p)=(B-p) e^{-r t}-\frac{c_{B}}{r}\left(1-e^{-r t}\right) .
\end{aligned}
$$

The outcome of the game if negotiations are terminated at time $t$ is denoted $\langle t, Q\rangle$ and yields payoffs of

$$
u_{S}(S, t, Q)=-\frac{c_{S}}{r}\left(1-e^{-r t}\right) u_{B}(B, t, Q)=-\frac{c_{B}}{r}\left(1-e^{-r t}\right)
$$

The traders seek to maximize their expected payoffs: neither risk aversion nor wealth effects are present.

As in Admati and Perry 1987, the players alternate making offers with a minimum time of $t^{0}$ between offers. Associated with each period of delay, then, is the discount factor $\delta=\mathrm{e}^{-r t^{\circ}}$ and per-period transaction costs for $S$ and $B$ of

$$
C_{S}=\frac{c_{S}}{r}\left(1-e^{-r t^{0}}\right) \approx c_{S} t^{0}, \quad C_{B}=\frac{c_{B}}{r}\left(1-e^{-r t^{0}}\right) \approx c_{B} t^{0} .
$$

$S$ begins the game by making an initial offer. After an offer is made, the other trader has three possible responses: (1) a counteroffer, in which case the game continues, (2) acceptance, in which case the game ends with trade occurring at the offered price, or (3) termination, in which case the game ends with both receiving a negative payoff equal to the accumulated transaction costs. The response can occur at any time after the minimum time between offers has passed. Suppose in round $i$ the offer $p_{i}$ is made after a delay $\Delta_{i}$ beyond the minimum time $t^{0}$ between offers. Then after $n$ rounds of play, the history $h^{n}$ is given by $\left\{\left(\Delta_{i}, p_{i}\right)\right\}_{i=1, \ldots, n}$. Throughout the paper, when I refer to an offer being accepted or a counteroffer being made "immediately" or "without delay," I mean that the action is taken with no additional delay beyond

6.The analysis can be extended to allow the traders' discount rates to differ, but equal discount rates is a natural assumption following from the presence of efficient capital markets. If their discount rates differ, the traders have an incentive for the one with the smaller discount rate to lend the other an arbitrarily large amount of money. 
the minimum time between offers (i.e., $\Delta_{i}=0$ ).

A pure strategy $\pi_{S}$ for $S$ specifies, after each history $h^{n}$ at which it is $S$ 's turn to move, a time delay $\Delta_{n+1}$ and whether to terminate negotiations, accept $p_{n}$, or make a counteroffer $p_{n+1}$. Similarly, define $\pi_{B}$ to be a pure strategy for $B$, and let $\pi=\left\{\pi_{S}, \pi_{B} \forall B\right\}$ be a profile of strategies for the traders. (Only pure strategies are considered.) The strategies $\pi$ result in an outcome $\langle t(B), p(B)\rangle$, which depends on the buyer's valuation $B$. The system of beliefs after any history $h^{n}$ is denoted $\mu=\{F(. \mid \cdot)\}$, where $F\left(. \mid h^{n}\right)$ is the belief that $S$ has about $B$ 's valuation conditional on the history $h^{n}$.

A sequential equilibrium (Kreps and Wilson 1982) for this game is a pair $(\pi, \mu)$ of strategies and beliefs, such that after every history $h^{n}$ each player's strategy is optimal given the other's strategy and her current beliefs about the other's valuation, and the beliefs are consistent with Bayes' rule.

The discounting of future payoffs plays an important role in the model. First, discounting and the assumption of no wealth effects implies that the time preferences are stationary, so that it is possible to determine a stationary equilibrium, in which the traders' strategies do not depend on time directly. Second, the discounting form means that delay may be a credible signal of strength for the buyer: a buyer with a high valuation is more impatient than a buyer with a low valuation. This is because the buyer's preferences satisfy the following single crossing property.

The buyer's utility function $u_{B}(B, t, p)$ is said to satisfy the single crossing property if utility is strictly monotone in $p$ and the slope of the indifference curve in $\langle t, p\rangle$ outcome space is strictly monotone in $B$. This means that the indifference curve of buyer $B^{\prime}$ is everywhere steeper than the indifference curve of buyer $B<B^{\prime}$, so that the indifference curves cross only once.

\section{LEMMA 1. The buyer's preferences satisfy the single crossing property.}

There are three useful implications of the single crossing property. First, if $B^{\prime} \geq B$, then $B^{\prime}$ expects in equilibrium to settle no later than $B$. This follows from the revelation principle and incentive compatibility. Second, for the maximization problem in which the buyer selects the optimal delay (time of trade) as a function of his private information, the first-order condition together with monotonicity of the choice function imply the second-order condition. Third, satisfaction of the first- and second-order conditions is sufficient for global optimality.

I now make two assumptions that will simplify the subsequent analysis.

Assumptions

(i) The discount rate exceeds the difference in the traders' transaction costs per unit time: $r>\mid c_{S}$ $c_{B} \mid$.

(ii) The minimum time between offers is arbitrarily small: $t^{0} \rightarrow 0(\delta \rightarrow 1)$.

Assumption (i) is required to guarantee that the split of the gains from trade under full information is strictly between 0 and 1 . If the difference in transaction costs per unit time exceeds the discount rate, then delay is not possible and the take-it-or-leave-it equilibrium results. Assumption (ii), that the minimum time between offers is arbitrarily small, is made to simplify some of the formulas. This is the interesting case, since in practice one observes a minimum response time that is small relative to plausible discount rates. Moreover, with an endogenous response time and full information each trader has an incentive to respond as quickly as possible to the other's offer. All the subsequent formulas change continuously as the minimum time between offers shrinks to zero and indeed are relatively insensitive to changes in the time between offers. Hence, the limiting results as $t^{0} \rightarrow 0$ closely approximate the results with small $t^{0}$. The formulas when $t^{0}>0(\delta<1)$ are easily calculated, but for the most part are omitted for brevity.

\section{Equilibrium Beliefs and Strategies}

Before stating the equilibrium, it is helpful to define several functions that determine the equilibrium offer, the acceptance decision, the delay decision, and the termination decision as a function of current beliefs.

An implication of this signalling equilibrium is that the offers after any history are Rubinstein offers given the current beliefs. Rubinstein 1982 shows that if it is common knowledge that $S$ 's valuation is $S$ and $B$ 's valuation is $B$, the alternating-offer game with a fixed time between offers has a unique subgameperfect equilibrium outcome in which the bargainers trade immediately and $S$ gets the share $x$ of the gains 
from trade $B$ - $S$ if $S$ makes the first offer or the share $y$ if $B$ makes the first offer. The Rubinstein shares are such that each trader is indifferent between trading at the other's offer immediately or trading at his own offer after a one period delay:

$$
y=\delta x-C_{S}, \quad 1-x=\delta(1-y)-C_{B}
$$

Solving these indifference equations for $x$ and $y$ yields

$$
x=\frac{1+C_{B}-\delta\left(1+C_{S}\right)}{1-\delta^{2}}, \quad 1-y=\frac{1+C_{S}-\delta\left(1+C_{B}\right)}{1-\delta^{2}},
$$

provided

$$
\frac{C_{B}}{1+C_{S}-\delta}<\delta<\frac{1+C_{B}}{1+C_{S}} \quad \text { and } \quad \frac{C_{S}}{1+C_{B}-\delta}<\delta<\frac{1+C_{S}}{1+C_{B}}
$$

so that $x$ and $y$ are between 0 and 1 . If $\delta<1$, then $x>y$ and there is an advantage to being the first to make an offer. This advantage vanishes as $\delta \rightarrow 1$. Taking the limit as $t^{0} \rightarrow 0$, yields

$$
x=y=\frac{1}{2}\left(1-\frac{c_{S}-c_{B}}{r}\right), \quad 1-x=1-y=\frac{1}{2}\left(1+\frac{c_{S}-c_{B}}{r}\right) .
$$

so long as $r>\left|c_{S}-c_{B}\right|$. Thus, if $S$ thinks the buyer's value is $B$, then along the equilibrium path $S$ makes the offer $p(B)=x B$. The equilibrium split of the gains from trade differs from an equal split only to the extent that the transaction costs of the parties differ. If the parties transaction costs are close relative to the discount rate, then the equilibrium will be close to an equal split of the gains from trade. This is in sharp contrast to the equilibrium without discounting, which gives all the gains from trade to the party with the smaller transaction cost, regardless of how small the difference in transaction costs is. This is a main reason why the equilibrium here differs from that of Perry 1986.

Now turn to the case where $B$ 's value is still uncertain. Then $B$ 's acceptance decision reveals information to $S$ : a less patient buyer accepts the offer, whereas a more patient buyer rejects the offer. Let $b(p)$ be the buyer type that is indifferent between accepting or rejecting the offer $p$. I will show that $b$ 's best alternative is to counter immediately with the offer $p(b)$, which $S$ accepts. Therefore, $b$ must be indifferent between $p$ today and $p(b)$ tomorrow:

$$
b-p=(1-x) b \quad \text { or } \quad b=\frac{p}{x} .
$$

A buyer $B<b(p)$ prefers to delay before making the revealing offer $p(B)$. Suppose $S$ infers $B$ 's value is $B(\Delta, b)$ if $B$ delays $\Delta$ before making the offer $p(B)$ and $S$ thinks that $B \geq b$ would have accepted $S$ 's offer. The length of delay $\Delta=B^{-1}(B, b)$ required to signal $B$ credibly is given by the incentive constraint

$$
\left.v(B, \Delta)=e^{v(B, \Delta,}\left[B=\max _{\Delta} 4 \beta\right]-\beta^{\prime}\right) \text { where } \beta=\frac{c_{B}}{r} \text {. }
$$


This says that $B$ does best by delaying for $\Delta(B, b)$ before making the offer $p(B)$. Taking the derivative of $B$ 's payoff with respect to $\Delta$ yields the separable first-order differential equation

$$
\frac{d B}{d \Delta}=-\frac{r}{\omega}(B+\gamma) \quad \text { where } \quad \omega=\frac{x}{1-x} \quad \text { and } \quad \gamma=\frac{2 c_{B}}{r+c_{S}-c_{B}}
$$

with the initial condition $B(0, b)=b$. The optimal delay is then found by integration:

$$
\Delta(B, b)=\int_{b}^{B}-\frac{\omega}{r} \frac{d B}{B+\gamma}=-\frac{\omega}{r} \log \frac{B+\gamma}{b+\gamma} .
$$

Hence, the discount factor associated with the buyer delaying $\Delta(B, b)$ to signal $B$ is

$$
D(B, b)=e^{-r \Delta(B, b)}=\left(\frac{B+\gamma}{b+\gamma}\right)^{\omega} .
$$

The buyer $B(\Delta, b)$ makes an offer at time $\Delta$, where $B(\Delta, b)$ is the inverse of the delay function:

$$
B(\Delta, b)=(b+\gamma) e^{-r \Delta / \omega}-\gamma
$$

By the signal crossing property of Lemma 1 , since $\Delta(\cdot, b)$ and hence $\mathrm{B}(\cdot, b)$ are strictly decreasing, the first-order condition is necessary and sufficient for the buyer's optimization problem.

If $B$ 's transaction costs are too high relative to discounting costs, $B$ is better offer terminating negotiations than trading after he has signaled his information. In particular, $B$ must get a positive payoff in order not to terminate negotiations:

$$
v(B, b)=e^{-r \Delta(B, b)}[(1-x) B+\beta]-\beta \geq 0 .
$$

Since $\beta=(1-x) \gamma$, this constraint simplifies to

$$
\frac{(B+\gamma)^{\omega+1}}{(b+\gamma)^{\omega}} \geq \gamma
$$

which is satisfied for $B \geq b^{\circ}(b)$ where

$$
b^{0}(b)=\gamma^{(1-x)}(b+\gamma)^{x}-\gamma,
$$

since $x=\omega /(\omega+1)$.

Finally, we turn to $S$ 's choice of an initial offer. Since $S$ does not have any private information, $S$ is best off making an offer without delay. This offer must be optimal given the response by the buyer. By offering $p(b)=x b, B \geq b$ immediately accepts and $\mathrm{B}<\mathrm{b}$ rejects and counters with $p(B)$ after payoffs have been discounted by $D(B, b)$. Thus, $S$ chooses $p(b)$, and hence $b$, to solve

$$
\begin{gathered}
b \in \underset{B}{\arg \max }(1-F(B)) x B+U(B) \quad \text { where } \\
u(b)=\int_{b^{0}(b)}^{b}[(x B+\sigma) D(B, b)-\sigma] d F(B) \quad \text { and } \sigma=\frac{c_{S}}{r}
\end{gathered}
$$

$S$ always prefers to make an offer rather than terminate negotiations. Offering $p=0$ does as well as termination, and hence the optimal offer $p(b)$ must do at least as well as termination. If $B$ has a significant cost advantage, $S$ may wish to terminate negotiations if $p(b)$ is not immediately accepted by $B$; that is, $S^{\prime} \mathrm{s}$ 
continuation value $u(b)$ following a rejection by $B$ may be negative. The Admati-Perry extensive form, however, does not allow termination at this point: $S$ must wait for $B$ 's counteroffer before she can respond. This built-in commitment not to terminate is a weakness of this extensive form. However, $S$ only has an incentive to terminate when $B$ has a significant cost advantage. In the next section, I describe how the equilibrium changes if we allow $S$ to terminate negotiations if $B$ does not immediately accept $S$ 's initial offer.

We now can state formally the equilibrium in terms of the Rubinstein share $x$, the offer function $p(B)$, the acceptance decision $b(p)$, the termination decision $b^{\circ}(b)$, and the delay discount $D(B, b)$. All of these functions are summarized below in terms of $B^{\prime}$ s relative transaction cost $\beta$ and $B^{\prime}$ s relative cost advantage $\alpha$ :

$$
\begin{array}{ccc}
\alpha=\frac{c_{S}-c_{B}}{r}, & \beta=\frac{c_{B}}{r}, & x=\frac{1-\alpha}{2}, \\
p(B)=x B, & b(p)=p / x, & b^{0}(b)=\gamma^{1-x}(b+\gamma)^{\alpha}-\gamma, \\
\omega=\frac{x}{1-x}, & \gamma=\frac{\beta}{1-x}, & D(B, b)=\left(\frac{B+\gamma}{b+\gamma}\right)^{\omega} .
\end{array}
$$

\section{Equilibrium Strategies and Beliefs}

\section{$S^{\prime}$ s Choice of an Initial Offer}

$(\pi 0)$ Strategy of $S$. $S$ offers $p(b)$ without delay where $b$ solves (U).

$B$ 's Response to $S$ 's Offer

Suppose $S$ just made an offer $p$ and $S$ believes at the time of the offer that $b^{\prime}$ is the highest buyer type. Let $b=\min \left\{b^{\prime}, p / x\right\}$.

$(\pi B)$ Strategy of $B$. Let $b^{\circ}=b^{\circ}(b)$.

(i) If $B \geq b$, then accept $p$ without delay provided $p \leq p(b)$, and otherwise immediately counter with $p(b)$.

(ii) If $b^{\circ}<B<b$, then counteroffer $p(B)$ after delaying $\Delta(B, b)$.

(iii) If $B \leq b^{\circ}$, then terminate negotiations.

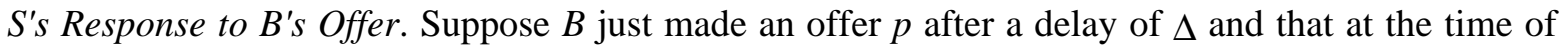
$S$ 's last offer $S$ believed that $B$ 's value was $b$.

$(\mu S)$ Belief of $S$. Following $B$ 's counteroffer $S$ believes $B$ 's value is $B(\Delta, b)$ with probability one.

$(\pi S)$ Strategy of $S$. Let $B=B(\Delta, b)$.

(i) If $p \geq p(B)$, then accept $p$ without delay.

(ii) If $p<p(B)$, then immediately counter with $p(B)$.

It remains to verify that the above strategies and beliefs form an equilibrium. This is done in the following propositions. First suppose that $S$ made the offer $p$ and it is now $B^{\prime}$ s turn to respond. Proposition 1 shows that $B$ 's best response takes one of three forms depending on his valuation.

PROPOSITION 1. In the subgame after $S$ has made an offer $p$, the beliefs $(\mu S)$ and strategies $(\pi S)$ and $(\pi B)$ form an equilibrium. Along the equilibrium path, $B$ accepts $p$ without delay if $B \geq b(p), B$ counteroffers with $p(B)$ after a delay of $\Delta(B, b(p))$ if $b^{\circ}(b(p))<B<b(p)$, and $B$ terminates negotiations if $B \leq b^{\circ}(b(p))$. The offer $p(B)$ is accepted by $S$ without delay.

A remarkable feature of this equilibrium is that, after $S$ 's initial offer, the equilibrium strategies and beliefs do not depend on the distribution $F$. S's initial offer, however, given in Proposition 2, does depend on $F$.

PROPOSITION 2. The beliefs $(\mu S)$ and strategies $(\pi 0),(\pi B)$, and $(\pi S)$ form an equilibrium. Along the equilibrium path $S$ makes an initial offer $p(b)$ without delay, where b solves $(U)$. 


\section{An Example with Uniform Uncertainty}

In this section, I show how the bargaining outcome depends on the cost parameters. In order to do this it is necessary to specify a distribution of uncertainty, so that the seller's initial offer can be determined. In particular, suppose the buyers' valuation is uniformly distributed on $[0,1]$. Then the continuation value $u(b)$ following rejection is

$$
\begin{aligned}
u(b) & =\int_{b^{0}(b)}^{b}\left[(x B+\sigma)\left(\frac{B+\gamma}{b+\gamma}\right)^{\omega}-\sigma\right] d B \\
& =x J(b)-\sigma\left[b-b^{0}-I(b)\right],
\end{aligned}
$$

where

$$
I(b)=\int_{b^{0}}^{b}\left(\frac{B+\gamma}{b+\gamma}\right)^{\omega} d B=\frac{1}{\omega+1}\left[b+\gamma-\frac{\left(b^{0}+\gamma\right)^{\omega+1}}{(b+\gamma)^{\omega}}\right]=(1-x) b,
$$

since

$$
\frac{1}{\omega+1}=1-x \quad \text { and } \quad \frac{\left(b^{0}+\gamma\right)^{\omega+1}}{(b+\gamma)^{\omega}}=\gamma
$$

and

$$
J(b)=\int_{b^{0}}^{b} B\left(\frac{B+\gamma}{b+\gamma}\right)^{\omega} d B=(1-x)\left[b(b+\gamma)-b^{0} \gamma-\frac{1-x}{2-x}\left((b+\gamma)^{2}-\left(b^{0}+\gamma\right) \gamma\right]\right.
$$

The optimal offer $p(b)=x b$ is determined by finding $b$ that maximizes $(1-b) x b+u(b)$. Taking the derivative with respect to $b$ and substituting $\sigma=(1+\gamma)(1-x)-x$ yields the first-order-condition

$$
(z+b-1)(1+b / \gamma)^{1-x}+x / 2-z=0 \quad \text { where } \quad z=(1+\gamma)(1-x)^{2}
$$

It is easy to verify that $S$ s payoff is strictly concave in $b$, so the first-order-condition uniquely determines $b$. This equation is solved numerically using Newton's method, once $\alpha$ and $\beta$ are specified. 


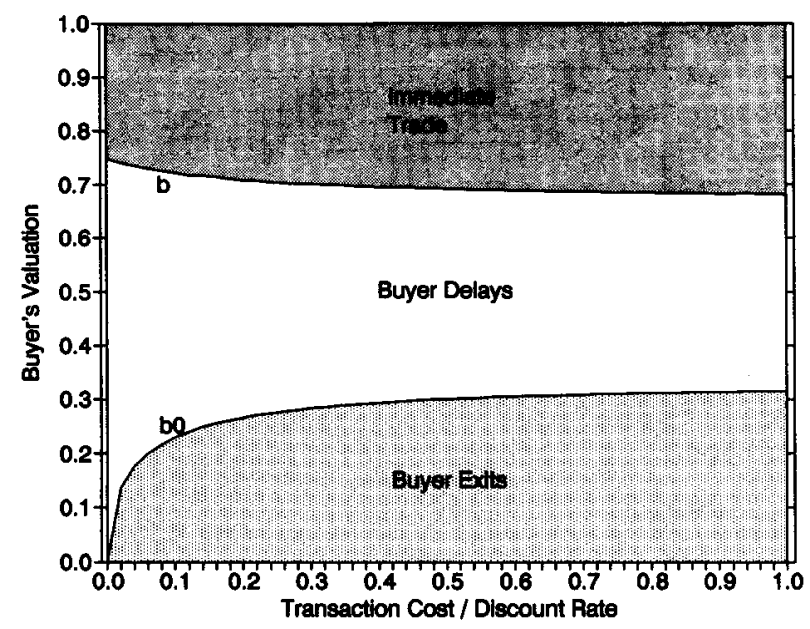

FiGURE 1. Bargaining Outcome Given Transaction Costs $(\alpha=0)$.

First, suppose $S$ and $B$ have the same transaction cost, so that $B$ 's cost advantage $\alpha$ is zero. Figure 1 shows the bargaining outcome as this transaction cost increases from 0 . At $\beta=0$, S makes the offer $1 / 2$, which is accepted by $B \geq 3 / 4$. If $B<3 / 4$, the buyer delays before making an acceptable offer. As the transaction cost increases, $b$ converges to $2 / 3$ and $b^{\circ}$ converges to $1 / 3$. In this uniform example, when the bargainers have equal and positive transaction costs, roughly $1 / 3$ of the bargains result in immediate trade, $1 / 3$ involve delayed trade, and $1 / 3$ end without trade.

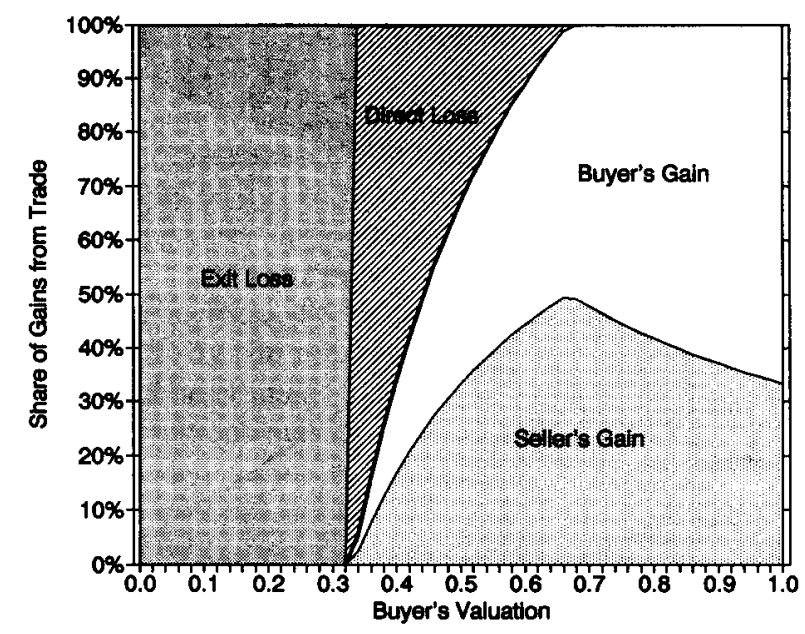

Figure 2. Ex Post Allocation of Gains from Trade with Large Transaction Costs $(\sigma=\beta=10)$.

Figure 2 depicts the ex post allocation of the gains from trade for this case when transaction costs are large relative to discounting. The equilibrium involves significant delay even when transaction costs are large relative to discounting. For buyer valuations greater than $2 / 3$, the buyer gets more than half the gains, since trade occurs immediately at a price of $1 / 3$. For $B$ between $1 / 3$ and $2 / 3$, the buyer rejects the initial offer of $1 / 3$ and delays before making the offer $B / 2$. The gains are split equally in this case, but there is a direct loss due to transaction costs, which increases from $0 \%$ of the gains at $B=2 / 3$ to $100 \%$ of the gains at $B=1 / 3$. For $B \leq 1 / 3$, the buyer immediately terminates negotiations, since the transaction costs that must be incurred to signal his value exceed $B$ 's share of the gains from trade.

Figure 3 shows the ex ante allocation of the gains from trade as the transaction cost increases from zero. With $\beta=0,18.7 \%$ of the gains from trade are lost as a result of delayed trade, the remaining $81.2 \%$ 
is split nearly equally between the buyer $(43.7 \%)$ and the seller $(37.5 \%)$. As $\beta$ increases to $\infty$, the inefficiency increases to $22.2 \%$ of which half is attributable to buyer termination and half to transaction costs. Both traders' shares of the gains are remarkably insensitive to the magnitude of transaction costs relative to discounting. The buyer's share of the gains gradually increases to $44.4 \%$, whereas $S$ 's share decreases to $33.3 \%$ as $\beta \rightarrow \infty$.

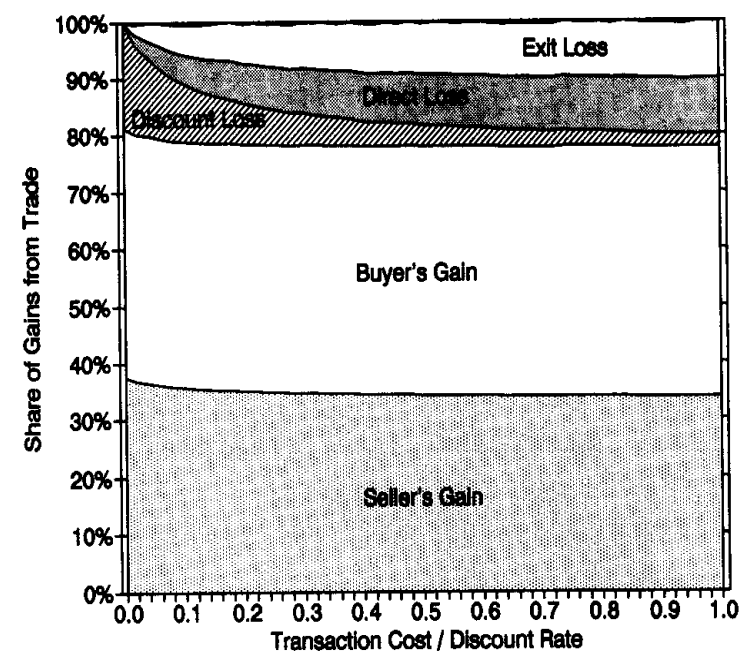

FIGURE 3. Ex Ante Allocation of Gains from Trade Given Transaction Costs $(\alpha=0)$

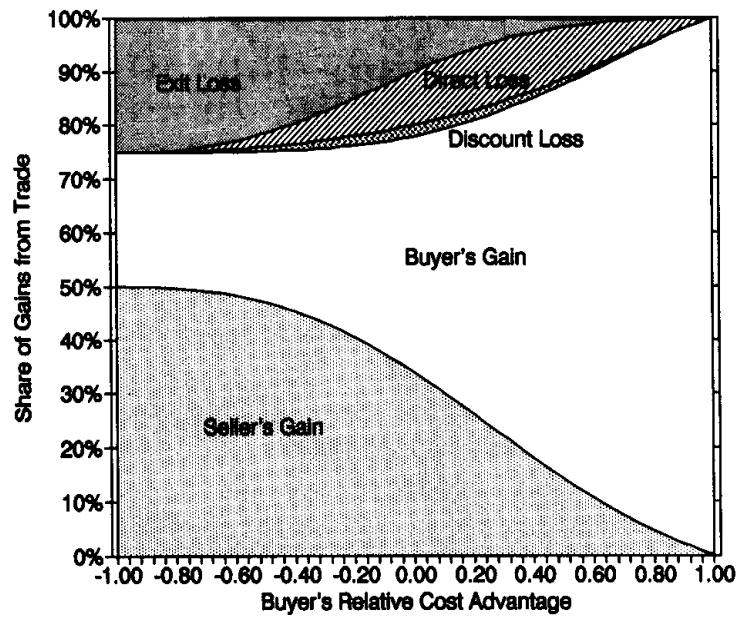

Figure 4. Ex Ante Allocation of Gains from Trade Given Buyer's Cost Advantage $(\beta=1)$.

Now consider what happens as $S$ 's transaction cost is varied, while holding $B$ 's cost fixed. Figure 4 shows the ex ante allocation of the gains from trade with $\beta=1$ as $B$ 's cost advantage $\alpha$ increases from - 1 to 1 (i.e, $S$ 's relative transaction cost increases from 0 to 2 ). When the seller has a large cost advantage, the outcome is the same as in Perry 1986. This is because the Rubinstein split is 1-0, and so $B$ accepts any offer $p \leq B$ and terminates otherwise. Hence, $S$ 's optimal offer $p^{*}$ maximizes $(1-p) p$, so $p^{*}=1 / 2$. As $B$ 's cost advantage increases from $-1, S$ 's share of the gains declines, whereas $B$ 's share increases. $B$ 's increase more than compensates for $S$ 's decrease, so there is a net increase in efficiency as $S$ 's cost advantage declines. At $\alpha=-1$, all the lost gains from trade are due to exit, but as $\alpha$ increases the direct loss due to transaction costs becomes important and eventually dominates the exit loss. 
When $B$ has a large cost advantage, it would seem that $S$ should be given the opportunity to terminate negotiations if $B$ does not immediately accept $S$ s offer. Allowing termination at this point introduces two possibilities. First, the continuation value $u\left(\min \left\{1, p^{*} / x\right\}\right)$ following rejection of the offer $p^{*}$ may be negative, in which case $S$ can credibly commit to terminating negotiations if $B$ rejects $p^{*}$. This is the case for $\alpha \geq .823$. Second, when $\alpha$ is between .632 and .823 , termination after the offer $p^{*}$ is not credible, but $S$ can make a lower offer $p\left(b^{*}\right)$, which makes termination credible. In particular, $S$ can choose $b^{*}$ to solve

$$
b^{*} \in \underset{B}{\arg \max }\{(1-F(x B)) x B \mid u(B) \leq 0\} .
$$

In this case, it is no longer true that $S$ prefers to have a low transaction cost: having a higher transaction cost is beneficial to $S$, since it makes it easier for $S$ to commit to terminating negotiations. This reversal of the comparative static is similar to the reversal in Nalebuff's 1987 analysis of pretrial negotiation. In Nalebuff 1987, the defendant inflates her opening offer to limit the amount of bad news rejection conveys, thereby making the threat to litigate credible. Here the seller deflates her opening offer to increase the amount of bad news from rejection, making the threat to terminate credible.

\section{Conclusion}

As demonstrated in Perry 1986, delay cannot have a signalling role when the sole source of impatience is a constant transaction cost per unit time. Trade occurs immediately at a take-it-or-leave-it price, or not at all. This result stems from two facts: (1) signalling is not possible since the cost of delay for every type of trader is the same, and (2) the Rubinstein offers with full information give all the gains to the party with the smaller transaction cost.

When discounting is added as a second source of impatience, both factors driving the Perry result change. The cost of delay is greater for a buyer with a higher value, so delay is a potential signal. Second, the Rubinstein solution varies continuously from a fifty-fifty split as the difference in the bargainers' transaction costs increases from zero. This yields an equilibrium outcome that has the prominent features of both the discounting and transaction cost models. In contrast to Perry 1986, the equilibrium may involve significant delay even when the transaction costs are large relative to discounting.

I conclude with several remarks about the bargaining outcome with uniform uncertainty when both transaction costs and discounting are present: - Agreements may occur rapidly compared to the outcome in the pure discounting model. Hence, empirical tests of the signalling model that ignore transaction costs may be misleading. One must be cautious not to reject the signalling model based on empirical settlement rates that are too fast compared with the pure discounting model. The rapid settlement rates may simply be due to positive transaction costs.

- As transaction costs increase, the duration of negotiations decreases and the frequency of termination increases.

- As transaction costs increase, the seller's ex ante payoff declines slowly and the buyer's payoff increases slowly. On net, the bargaining efficiency declines as transaction costs increase but the decline is small.

- Termination of negotiations may occur as a result of positive transaction costs. The termination, however, always occurs at the outset of negotiations. This is because the buyer has full information about the size of the gains from trade and hence how the negotiation will proceed. With two-sided uncertainty, this would not be the case and termination might well occur after some amount of bargaining.

- Patience is usually a virtue: as the buyer's cost advantage increases, the seller's payoff declines and the buyer's payoff increases. Eventually, however, the seller benefits from higher transaction costs if we assume the seller is allowed to terminate negotiations if the buyer does not immediately accept the seller's initial offer. This happens when the seller's transaction cost is so high that she can credibly commit to terminating negotiations if her initial offer is not 
accepted. A higher transaction cost, in this case, makes it easier for the seller to commit to walking away following a rejection by the buyer.

- Transaction costs may be used to make threats credible. For example, a seller may prefer to employ a costly agent to conduct the negotiation, so as to make credible the seller's threat to terminate negotiations if the initial offer is rejected. This point has empirical relevance. Threats to terminate negotiations if demands are not met are commonly observed in negotiations, yet termination is inconsistent with sequential rationality in the pure discounting model. Termination, however, arises naturally once transaction costs are introduced. ${ }^{7}$

\section{Appendix}

Proof of Lemma 1. For $B$, we have $u_{B}(B, t, p)=\mathrm{e}^{-r t}(B-p)-\left(c_{B} / r\right)\left(1-\mathrm{e}^{-r t}\right)$. Hence, $B$ 's payoff is strictly decreasing in $p$, since $\partial u_{B} / \partial p=-\mathrm{e}^{-r t}<0$. The slope of the indifference curve is $-\left(\partial u_{B} / \partial t\right) /\left(\partial u_{B} / \partial p\right)=-r(B-p)-c_{B}$, which is strictly decreasing in $B$.

ProOF OF Proposition 1. I need to show that the beliefs $(\mu S)$ and strategies $(\pi S)$ and $(\pi B)$ constitute an equilibrium. That is, $S$ 's strategy $(\pi S)$ is optimal given her belief $(\mu S)$ and the strategy $(\pi B)$ of $B$, and $B$ 's strategy $(\pi B)$ is optimal given $S$ 's belief $(\mu S)$ and strategy $(\pi S)$. Only single-period deviations need to be checked to determine optimality, since each player's optimization problem is a dynamic programming problem with discounting and bounded reward (Blackwell 1965).

To verify the optimality of $(\pi S)$ given $(\mu S)$ and $(\pi B)$, suppose $B$ just made an offer $p$ after a delay of $\Delta$ and that at the time of $S$ 's last offer $S$ believed that $B$ 's value was $b$. From $(\mu S), S$ believes that $B$ 's valuation is $B=B(\Delta, b)$. From $(\pi B)$, then, $B$ will accept any offer $p \leq p(B)$ and otherwise will counteroffer $p(B)$ without delay. Hence, $S$ 's best counteroffer is to offer $\mathrm{p}(\mathrm{B})$ without delay, which is accepted by $B$. $S$ 's best response to $p$, then, is to accept if $p \geq p(B)$ and otherwise counter with $p(B)$, so $(\pi S)$ is optimal.

To verify that $(\pi B)$ is optimal given $(\mu S)$ and $(\pi S)$, suppose $S$ just made an offer $p$ and $S$ believes at the time of the offer that $b^{\prime}$ is the highest buyer type. Let $b=\min \left\{b^{\prime}, p / x\right\}$. If $B$ counteroffers after a delay of $\Delta$, then by $(\mu S) S$ believes the buyer's value is $B^{\prime}=B(\Delta, b)$. B's optimal offer, then, is $p\left(B^{\prime}\right)$ : offering $p^{\prime}>p\left(B^{\prime}\right)$ yields less, since both $p^{\prime}$ and $p\left(B^{\prime}\right)$ are accepted with probability one by $(\pi S)$; similarly, offering $p^{\prime}<p\left(B^{\prime}\right)$ yields less, since $S$ counters immediately with $p\left(B^{\prime}\right)$, which $B$ accepts, since only single-period deviations need be considered. It remains to determine the optimal delay, given that $p\left(B^{\prime}\right)$ is the optimal offer after a delay of $\Delta . B^{\prime}$ s payoff from offering $p\left(B^{\prime}\right)$ after a delay of $\Delta$ is

$$
v(\Delta)=e^{-r \Delta}\left(B-p\left(B^{\prime}\right)\right)-\beta\left(1-e^{-r \Delta}\right),
$$

where

$$
p\left(B^{\prime}\right)=x B^{\prime} \quad \text { and } \quad B^{\prime}=(b+\gamma) e^{-r \Delta / \omega}-\gamma .
$$

Hence,

$$
v(\Delta)=e^{-r \Delta}(B+\gamma)-x e^{-r \Delta / x}(b+\gamma)-\beta,
$$

since $\beta=\gamma(1-x)$ and $x=\omega /(\omega+1)$. The marginal utility of waiting is then

$$
\frac{d v}{d \Delta}=-r e^{-r \Delta}\left[B+\gamma-(b+\gamma) e^{-r \Delta / \omega}\right]
$$

Case (i). Suppose $B \geq b$. In this case, the marginal utility of waiting is negative for all $\Delta>0$, so the optimal delay is $\Delta=0$. Hence, (i) is optimal.

Case (ii). Suppose $b^{\circ}<B<b$. For $B<b$, the marginal utility of waiting is positive if $\Delta<\Delta(B, b)$ and negative for $\Delta>\Delta(B$, $b$ ). Hence, the optimal delay is $\Delta(B, b)$. The buyer, however, may prefer to terminate negotiations. $B$ 's payoff from the optimal delay is

7.Supported by the National Science Foundation grant SES89-21625. 


$$
(1-x)\left[\frac{(B+\gamma)^{\omega+1}}{(b+\gamma)^{\omega}}-\gamma\right]
$$

which is positive so long as $B \geq b^{\circ}$. Thus, (ii) is optimal.

Case (iii). Suppose $B \leq b^{\circ}$. In this case, the optimal delay is $\Delta(B, b)$, but $B$ 's payoff from continuing is negative. Hence, $B$ is best off terminating negotiations and (iii) is optimal.

Proof of Proposition 2. The optimality of $(\pi S)$ and $(\pi B)$ is verified in Proposition 1 . Hence, it remains to determine $S$ 's optimal offer. Since by $(\pi B) B$ 's response to $S$ 's offer is independent of $S$ 's delay, it is best for $S$ to make the offer without delay. From $(\pi B)$, if $S$ offers $p(b)=x b$, then $S^{\prime}$ s expected payoff is $(1-F(b)) x b+u(b)$, where

$$
u(b)=\int_{b^{0}(b)}^{b}[(x B+\sigma) D(B, b)-\sigma] d F(B) .
$$

$S^{\prime}$ s best response is to choose $b$ to maximize this expected payoff. Termination is never better than $x b$, since the optimal offer yields at least 0 . Hence, $x b$ is $S^{\prime \prime}$ s best offer.

\section{References}

ADMATI, A. R., and M. PERRY, “Strategic Delay in Bargaining,” Review of Economic Studies, 54 (1987), 345-364.

AUSUBEL, L. M., and R. J. DENECKERE, "Stationary Sequential Equilibria in Bargaining with Two-Sided Incomplete Information," Working Paper, Northwestern University, 1988a.

AUSUBEL, L. M., and R. J. DENECKERE, "Efficient Sequential Bargaining,” Working Paper, Northwestern University, 1988 b.

AUSUBEL, L. M., and R. J. DENECKERE, “A Direct Mechanism Characterization of Sequential Bargaining with One-Sided Incomplete Information," Journal of Economic Theory, 48 (1989a), 18-46.

AUSUBEL, L. M., and R. J. DENECKERE, "Reputation in Bargaining and Durable Goods Monopoly," Econometrica, 57 (1989b), 511-532.

BINMORE, K., M. J. OSBORNE, and A. RUBINSTEIN, "Noncooperative Models of Bargaining." In Handbook of Game Theory with Economic Applications, (R. J. Aumann and S. Hart, eds.), North-Holland, Amsterdam, 1991.

BLACKWELL, D., "Discounted Dynamic Programming," Annals of Mathematical Statistics, 36 (1965), $226-235$.

CHATTERJEE, K., and L. SAMUELSON, "Bargaining with Two-Sided Incomplete Information: An Infinite-Horizon Model with Alternating Offers," Review of Economic Studies, 54 (1987), 175-192.

CHO, I., "Uncertainty and Delay in Bargaining," Review of Economic Studies, 57 (1990), 575-596.

CRAMTON, P. C., "Bargaining with Incomplete Information: An Infinite-Horizon Model with Continuous Uncertainty," Review of Economic Studies, 51 (1984), 579-593.

CRAMTON, P. C., "Sequential Bargaining Mechanisms." In Game Theoretic Models of Bargaining, (A. Roth, Ed.), Cambridge University Press, Cambridge, England, 1985.

CRAMTON, P. C., "Strategic Delay in Bargaining with Two-Sided Uncertainty," Review of Economic Studies, 58 (1991), forthcoming.

CRAMTON, P. C., and J. S. TRACY, "Strikes and Delays in Wage Bargaining: Theory and Data," NBER Working Paper, 1990.

CROSS, J. G., The Economics of Bargaining, Basic Books, New York, NY, 1969.

FUDENBERG, D. LEVINE and J. TIROLE, "Infinite-Horizon Models of Bargaining with One-Sided Incomplete Information." In Game Theoretic Models of Bargaining, (A. Roth, Ed.), Cambridge University Press, Cambridge, England, 1985.

FUDENBERG, D., and J. TIROLE, "Sequential Bargaining with Incomplete Information," Review of Economic Studies, 2 (1983), 221-247.

Grossman, S. J., and M. Perry, "Sequential Bargaining Under Asymmetric Information," Journal of Economic Theory, 39 (1986), 120-154.

GUL, F., and H. SONNENSCHEIN, “On Delay in Bargaining with One-Sided Uncertainty,” Econometrica, 56 (1988), $601-612$.

GUL, F., H. SONNENSCHEIN, and R. WILSON, "Foundations of Dynamic Monopoly and the Coase Conjecture," Journal of Economic Theory, 39 (1986), 155-190.

HART, O. "Bargaining and Strikes," Quarterly Journal of Economics, 104 (1988), 25-44.

KENNAN, J., and R. WILSON, "Bargaining with Private Information," Journal of Economic Literature, (1991), forthcoming.

KENNAN, J., and R. WILSON, "Strategic Bargaining Models and Interpretation of Strike Data," Journal of Applied Econometrics, 4 (1989), S87-S130.

KREPS, D. M., and R. WILSON, “Sequential Equilibria,” Econometrica, 50 (1982), 863-894.

NALEBUFF, B., “Credible Pretrial Negotiation,” Rand Journal of Economics, 18 (1987), 198-210.

OSBORNE, M. J., and A. RUBINSTEIN, Bargaining and Markets, Academic Press, Boston, 1990.

PERRY, M., "An Example of Price Formation in Bilateral Situations: A Bargaining Model with Incomplete Information," Econometrica, 54 (1986), 313-322.

PERRY, M., and P. RENY, "Non-cooperative Bargaining without Procedures," Working Paper, University of Western Ontario, 1989. 
RUBINSTEIN, A., “A Bargaining Model with Incomplete Information about Time Preferences,” Econometrica, 53 (1985), 11511172.

RUBINSTEIN, A., "Perfect Equilibrium in a Bargaining Model," Econometrica, 50 (1982), 97-109.

SAMUELSON, W., "Bargaining Under Asymmetric Information,” Econometrica, 52 (1984), 995-1005.

SOBEL, J., and I. TAKAHASHI, “A Multistage Model of Bargaining,” Review of Economic Studies, 50 (1983), 411-426.

VINCENT, D.R., "Bargaining with Common Values," Journal of Economic Theory, 48 (1989), 47-62. 


\section{Peter C. Cramton}

\section{Hoover Institution, Stanford University, Stanford, CA 94305}

Michael Horvath discovered an error on page 1225 of Cramton (1991). The first two equations of $\S 3$, which determine the Rubinstein shares, assume that the gains from trade are 1. More generally, with a seller valuation of $S$ and a buyer valuation of $B$, the gains from trade are $B-S$ and the first two equations of $\S 3$ should be

$$
y(B-S)=\delta x(B-S)-C_{S}, \quad(1-x)(B-S)=\delta(1-y)(B-S)-C_{B} .
$$

To simplify, assume $S=0$, so that the gains from trade are $B$. Solving for $x$ and $y$ and then taking the limit as the time between offers goes to zero yields the Rubinstein share to the seller

$$
x=\frac{1}{2}+\frac{c_{B}-c_{S}}{2 r B},
$$

so long as $r B>\left|c_{B}-c_{S}\right|$. The seller's share differs from $1 / 2$ to the extent the bargainers' transaction costs differ. However, the importance of a difference in the transaction costs depends on the rate of discounting $r$ and the size of the gains from trade $B$. As $B$ increases, the difference in the transaction costs $\left(c_{B}-c_{S}\right)$ becomes less important, since the loss from discounting $(r B)$ increases.

The dependence of the Rubinstein share on the size of the gains from trade effects the delay decision by the buyer as well as the buyer's decision to negotiate. In particular, the formulas for $D(B, b)$ and $b^{0}(b)$ are

$$
D(B, b)=\frac{c+r B}{c+r b} \quad \text { and } \quad b^{0}(b)=\frac{1}{r}\left(-c+\sqrt{2 c_{B}(c+r b)}\right)
$$

where $c=c_{S}+c_{B}$.

The example of $\S 4$ is also effected if $c_{S} \neq c_{B}$. The seller's continuation value is

$$
u(b)=-\frac{c_{s}}{r}\left(b-b^{0}(b)\right)+\frac{1}{2 r} \int_{b^{0}(b)}^{b} \frac{(c+r B)^{2}}{c+r b} d B,
$$

and the first-order-condition for the optimal $b$ is

$$
3 r-4 r b-c+\left(3 c_{S}-c_{B}\right) \sqrt{2 c_{B} /(c+r b)}=0 .
$$

Figures 1-3 do not change, since they assume $c_{S}=c_{B}$. Figure 4 changes in two ways. First, the equilibrium is valid over a smaller set of parameters, as a result of the constraint $r b^{0}(b)>\left|c_{S}-c_{B}\right|$. Second, the inefficiency of the bargain does not vanish as the buyer's cost advantage increases. This is because the buyer must convince the seller through delay that the buyer's share should be large.

\section{References}

CRAmton, Peter C., "Dynamic Bargaining with Transaction Costs," Management Science, 37 (1991), 1221-1233. 